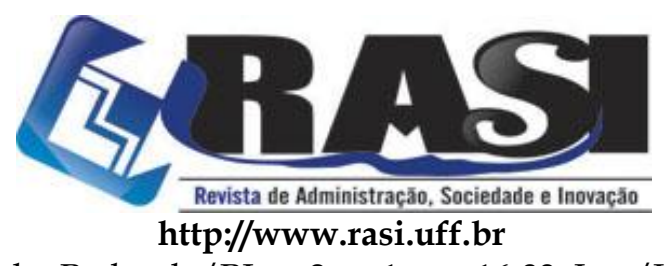

RASI, Volta Redonda/RJ, v. 2, n. 1, pp. 16-33, Jan./Jun. 2016

\title{
Fatores Intervenientes no Processo de Decisão na Percepção dos Hóspedes de uma Pousada
}

Reginaldo Adriano de Souza, Rodolpho Xavier Heiderich, Anandy kassis de Faria AlvinHannas, Luiz Gustavo Leite Souza, Fernando Albuquerque Miranda

\section{RESUMO}

Conhecer o consumidor e sua percepção sobre as organizações e seus serviços é fundamental para sobreviver no atual mercado competitivo. Dentro dessa realidade, esta pesquisa quantitativa realizada em 2014 focou-se nas respostas fornecidas por turistas brasileiros que estavam hospedados na pousada Vale do Caparaó, no município de Alto Caparaó (Minas Gerais, Brasil). Por meio de questionários estruturados, aplicados a 97 usuários dos serviços prestados, objetivou-se verificar as percepções dos turistas sobre a Pousada Vale do Caparaó e os fatores que os levaram a escolher essa opção de hospedagem. A cada dia, os consumidores detêm uma maior quantidade de informações e se dirigem a uma posição mais privilegiada na relação com as empresas. É o consumidor quem já está ditando as regras em diversos segmentos do mercado, devido ao fato de estar mais bem informado sobre os produtos e a concorrência entre as empresas. No turismo não é diferente, o consumidor tem buscado saber a cada dia mais sobre a escolha dos melhores serviços com uma boa relação de custo/benefício, fazendo assim com que todos os setores turísticos se atentem sobre as vontades do consumidor. A pesquisa abordada apresentou diversos fatores com base nas informações dos clientes, desde sua infraestrutura até atendimento, demonstrando assim que os principais aspectos levados em consideração foram a infraestrutura considerada como superior, a facilidade de acesso, além disso, os clientes ainda julgaram justo o valor pago pelos serviços.

PALAVRAS-CHAVE: Turismo; Hospedagem; Comportamento do consumidor.

\section{ABSTRACT}

Knowing the consumer and their perception about the organization and its services is essential to survive in today's competitive market. Within this reality this quantitative survey conducted in 2014 focused on the responses provided by Brazilian tourists who were staying at the Vale do Caparaó Inn in the city of Alto Caparaó (Minas Gerais, Brazil). Through structured questionnaires administered to 97 users of the services provided, aimed to verify the perception of tourists on the Pousada Vale do Caparaó and the factors that led them to choose this accommodation option. Every day consumers hold a greater amount of information and are directed to a more privileged position in relation to the companies. It is the consumer who is already dictating the rules in several market segments, due to the fact that the consumers are better informed about the products and also competition between companies. In the tourism it's not different, the consumer has sought to know every day more about the choice of the best services with a good cost / benefit ratio, thereby making all the tourist industries pay attention about what the consumer wants them to offer. The survey addressed presented several factors based on customer information, from its infrastructure to the attendance, thus demonstrating why consumers opt for that hosting services.

KEYWORDS: Tourism; Accommodation; Consumer behavior.

\section{Universidade U⿴囗十 Federal Fluminense}

R. Desembargador Ellis Hermydio Figueira, 783, Bloco A, sl. 218, Aterrado. 27213-415 - Volta Redonda, RJ - Brasil www.uff.br

Copyright (C) 2016 RASI. Todos os direitos, até mesmo de tradução, são reservados. É permitido citar parte de artigos sem autorização prévia, desde que seja identificada a fonte. 


\section{Fatores Intervenientes no Processo de Decisão na Percepção dos Hóspedes de uma Pousada}

\section{Introdução}

A sobrevivência das organizações é o principal objetivo das empresas no mercado competitivo e mutante em que se encontram. Com o passar do tempo, as empresas vêm se adaptando a essa situação, investindo alto no setor administrativo, fazendo assim com que ocorra uma grande mudança em toda estrutura organizacional, de forma que se busque excelência em todos os setores da organização. Essa postura é essencial, uma vez que a falta de planejamento é vista como uma das maiores causas de mortalidade das empresas (SEBRAE, 2008).

Lutando justamente contra essa falta de planejamento, o turismo, por sua vez, vem crescendo muito no país, fazendo altos investimentos em propagandas, atendimento, pacotes, recepção etc.; considerando todos os esforços para o crescimento do setor, a demanda por hospedagem tem crescido em ritmo acelerado, portanto, podese esperar que a qualidade de estada de uma pousada seja cada vez melhor do que o esperado a cada ano que se passa (TRIGUEIRO, 2009).

Uma precaução tomada é estar sempre acompanhando o consumidor, pois seus gostos mudam a todo o momento e as empresas que não se adaptam a essas mudanças, fecham suas portas para o mercado e somem como se nunca tivessem existido.

Nesse âmbito, a visão do cliente sobre uma pousada, determina como ela é vista pela sociedade e onde ela se destaca dentre as demais, mostrando o porquê de escolher e frequentar determinada pousada em meio a tantas outras.

Essa pesquisa abordou justamente quais os fatores que levam os clientes a frequentarem a pousada Vale do Caparaó, localizada na cidade de Alto Caparaó (MG); além dos motivos pelos quais não optam pelas outras pousadas, hotéis e albergues.

Este estudo teve por objetivos: (1) a avaliação comparativa da pousada Vale do Caparaó e seus concorrentes e também (2) conhecer os fatores quem influenciaram os turistas na escolha pela pousada estudada, fazendo, assim, com que ela possa atender a seus clientes da maneira com que eles pretendem ser tratados, aumentando sua eficácia em todos os serviços oferecidos, desde pacotes até sua recepção, podendo conhecer seus pontos mais fortes e fracos.

Este artigo também poderá auxiliar nas decisões da gerência de forma com que não sejam baseadas apenas na percepção, mas sim levando em conta dados que foram coletados com base na opinião do próprio cliente, reduzindo, dessa forma, a margem de erro no processo de tomada de decisão.

Na busca pela descoberta dos pontos críticos da pousada, bem como dos fatores motivacionais dos usuários na escolha por esta empresa, este trabalho foi dividido em três partes: (1) levantamento bibliográfico sobre os assuntos abordados; (2) metodologia utilizada para a coleta dos dados; (3) análise quantitativa dos questionários aplicados aos usuários e discussão dos resultados.

\section{Fundamentação Teórica}

2.1. Necessidades e desejos dos consumidores/usuários 
Entender o que leva um turista a sair de sua cidade e se deslocar a outra é fundamental para o sucesso do negócio turístico. Para isso, abordou-se a pirâmide de necessidades de Maslow, um psicólogo clínico que formulou uma teoria amplamente aceita acerca da motivação humana com base na noção de uma hierarquia universal das necessidades humanas (SHIFFMAN, KANUK, 2000).

\section{Necessidades \\ de auto-realização \\ (desenvolvimento \\ e realização pessoais)}

Necessidades de respeito

(auto-estima, reconhecimento, status)

Necessidades sociais

(senso de integração, amor)

Necessidades de segurança

(segurança, proteção)

Necessidades fisiológicas

(fome, sede)

Figura 1: Pirâmide de necessidades de Maslow.

Fonte: Kotler e Armstrong (2003. p.130).

Shiffman e Kanuk (2000) dizem que a teoria de Maslow postula cinco níveis básicos de necessidades humanas, conforme apresentado na FIGURA 1. Começando pelas necessidades fisiológicas, que é o nível mais básico e visa atender às necessidades fundamentais ligadas ao sustento da vida biológica, que incluem alimento, água, ar, abrigo, roupa e sexo. Segundo os autores, quando a pessoa tem satisfeita sua necessidade, ela muda para outro nível, nesse caso, migraria assim para as necessidades de segurança que se relacionam com os aspectos de segurança, de proteção, já que essas necessidades incluem ordem, estabilidade, rotina, familiaridade, controle sobre a vida e sobre o ambiente. O próximo nível da hierarquia de necessidades postula sobre as necessidades sociais, que são ligadas ao amor, ao afeto, ao relacionamento e à aceitação. As pessoas buscam relacionamentos humanos afetivos e satisfatórios com outras pessoas e são motivadas pelo amor de suas famílias. O nível seguinte pertence às necessidades egoístas, nesse nível, as necessidades são orientadas para dentro ou para fora, ou em ambas direções. As necessidades de ego orientadas para dentro refletem as necessidades de auto-aceitação, auto-afirmação, de sucesso, de independência, de satisfação pessoal com um trabalho bem feito. As necessidades orientadas para fora incluem, necessidades de prestígio, de reputação, de status e de reconhecimento pelos outros. O último nível dessa hierarquia pertence à necessidade de auto-realização, essa necessidade refere-se ao desejo de um indivíduo de satisfazer o seu potencial - de se 
tornar tudo o que ele é capaz de se tornar, sendo expressas de formas diferentes por pessoas diferentes.

\begin{abstract}
Necessidades humanas são estados de carência percebida. O homem tem muitas necessidades complexas: necessidades básicas físicas de alimentação, roupas, calor e segurança; necessidades sociais de fazer parte de um grupo e ser querido; necessidades individuais de conhecimento e auto-realização. Essas necessidades não são criadas pelos profissionais de marketing, são uma parte básica da constituição do homem. (KOTLER, 2000, p.3)
\end{abstract}

Para Trigueiro (2009), o turista é também consumidor de outros bens e serviços, logo, o produto turístico somente será consumido após os turistas terem satisfeitos suas necessidades primárias, como se alimentar, vestir-se.

De acordo com Kotler e Armstrong (2005), as compras do consumidor são extremamente influenciadas pelas suas características culturais, sociais, pessoais e psicológicas. O produto turístico é considerado supérfluo na escala de necessidades do indivíduo de acordo com a pirâmide de necessidades de Maslow. O turista só irá procurar pelos serviços de turismo e viagem quando tiverem as condições necessárias para que isso ocorra, como a existência de tempo livre e a disposição de recursos econômicos (TRIGUEIRO, 2009).

Um ponto relevante a ser discutido é a motivação do consumidor, para Schiffman e Kanuk (2000), a motivação é descrita como a força motriz intrínseca dos indivíduos que os levam a ação. Essa força é produzida por um estado de tensão, sua existência surge em função de uma necessidade ou desejo não satisfeito. Os turistas e os fatores que os motivam a viajar são muito diferentes entre si, variando desde suas personalidades individuais, seus diferentes estilos de vida, suas experiências passadas, suas condições financeiras, sua cultura, sua religião, seus filhos etc. Para Kotler e Armstrong (2005, p.129), "um motivo (ou impulso) é uma necessidade suficientemente forte para fazer com que a pessoa busque satisfazê-la". É muito provável que nenhum turista vá se influenciar por uma única motivação, geralmente, é mais provável que ele seja afetado por um conjunto de motivações em um dado momento (SWARBROOKE, HORNER, 2002).

Para Vaz e Perim (2001), se o homem moderno viaja a negócios, por prazer ou em busca de conhecimentos, as raízes dessa atividade ainda permanecem ligadas aquela necessidade ancestral de mudança, de descortinar novos horizontes e, com isso, amenizar problemas originados da civilização: o ambiente tenso das grandes cidades, a falta de momentos descompromissados. O homem está sempre buscando uma forma de se desligar do mundo, mudar hábitos e costumes e também vivenciar novas histórias para sair de sua monotonia.

Um dos maiores motivos que levam uma pessoa a viajar é o desprendimento da realidade, a necessidade de buscar novos horizontes, novas aventuras e novos conhecimentos. O mundo vem deixando as pessoas cada vez mais presas na monotonia de suas vidas, fazendo com que vivam de forma em que a pessoa se sinta presa a sua região, por motivos como trabalho e família. Uma viagem turística é uma forma de sair desse círculo vicioso, pois isso modifica totalmente a sua realidade, muda todos os seus costumes e também o local em que o consumidor é acostumado a viver. Segundo Swarbrooke e Horner (2002, p. 88), "o funcionário de um escritório olhando para fora da janela em um subúrbio de Londres em nossos dias pode ser motivado por um desejo 
de sair de férias e ir a qualquer lugar, para fugir de sua monotonia de rotina do trabalho".

Vaz e Perim (2001) postulam que o elemento que está na origem da motivação pode pertencer a uma ou algumas esferas de pressão como:

- Pessoal: em que uma pessoa faz turismo por um desejo pessoal de conhecer determinada localidade;

- Familiar: em que as pessoas têm compromissos com seus familiares, como comparecimento a algumas solenidades como formaturas e casamentos;

- Social: em que uma pessoa faz uma viagem por motivos de obrigações sociais, decorrentes da participação de grupos comunitários, esportivos, associativos em geral.

- Organizacional: em muitos casos, quando se tem envolvimento com alguma organização, ocorrendo quando um profissional tem de resolver determinada questão de interesse da organização, ou uma associação cujo presidente ou diretor deverá representar a instituição em algum congresso.

\title{
2.2. Satisfação dos usuários
}

Dentre os aspectos relevantes no relacionamento com o cliente, cabe abordar a satisfação do cliente, relacionando-os aos serviços de turismo. Por ser um assunto de diversa fundamentação, devem-se abordar alguns conceitos em relação à satisfação do turista.

\begin{abstract}
A satisfação do cliente depende do que ele percebe sobre o desempenho do produto em relação às suas expectativas. Se esse desempenho não corresponder às expectativas do cliente, o comprador ficará insatisfeito. Se exceder as expectativas, ele ficará maravilhado. As empresas referência em marketing se desdobram para manter seus clientes satisfeitos, pois clientes satisfeitos repetem as compras e contam aos outros suas boas experiências com o produto. Empresas inteligentes têm como objetivo maravilhar o cliente, prometendo somente aquilo que se pode oferecer e entregando mais do que ofereceram (KOTLER E ARMSTRONG, 2003, p.6).
\end{abstract}

Segundo Grönroos $2004^{1}$ apud Abdalla et al. (2009), os clientes ficam satisfeitos com a qualidade percebida desde que o sacrifício envolvido - preços e custos de relacionamento - não seja demasiadamente alto. Clientes satisfeitos podem tornar-se comprometidos com o fornecedor ou prestador de serviços porque confiam na outra parte ou porque estão contentes com o nível de sacrifício envolvido no relacionamento. Os clientes já existentes podem aumentar seu volume de negócios com o prestador de serviços e novos clientes serão atraídos para a organização.

Whiteley e Hessan (1996 p. 169) dizem que "a lealdade não é mais uma questão de hábito ou dever, mas de paixão. Você deve fazer as coisas tão surpreendentemente bem, que os clientes se tornem não meros defensores, mas sim consumados apóstolos". Um fator interessante é dizer também que a satisfação do cliente está estreitamente vinculada à qualidade. Para Kotler e Armstrong (2003), de maneira simplista, pode-se definir qualidade como ausência de defeito.

${ }^{1}$ GRÖNROOS, C. Marketing: gerenciamento e serviços. Rio de Janeiro: Elsevier, 2004. 
Um turista bem acomodado se sentirá satisfeito. O visitante primário sempre estará buscando qualidade da comida e da bebida, qualidade dos serviços, hospitalidade e um meio ambiente agradável. Já para os turistas reincidentes, a satisfação e a fidelização se dá devido à boa hospitalidade, à acomodação, à tranquilidade e a qualidade da comida e da bebida (CHAGAS; MARQUES JÚNIOR; BRANDÃO, 2011).

\title{
2.3. Comportamento do Consumidor
}

Falar sobre o comportamento do consumidor é dizer o porquê dos indivíduos tomarem decisões de como gastarem seus recursos disponíveis como tempo, dinheiro e esforço em itens relacionados ao consumo. O comportamento do consumidor engloba o estudo de o quê compram, porque compram, onde compram, com que frequência compram e com que frequência usam o que compram (SHIFFMAN; KANUK, 2000).

O comportamento do consumidor consiste nas atividades diretamente envolvidas na obtenção, no consumo e na distribuição de produtos e serviços, incluindo os processos de tomada de decisão que procedem e seguem essas ações (SWARBROOKE; HORNER, 2002).

\begin{abstract}
Diariamente, os consumidores tomam diversas decisões de compra. Muitas grandes empresas pesquisam essas decisões detalhadamente para saber o que, onde, como, quanto, quando e porque os consumidores compram. Os profissionais de marketing podem estudar as compras dos consumidores para descobrir o que, onde e quanto eles compram. Mas descobrir os motivos por trás do comportamento de compra deles não é uma tarefa fácil - as respostas geralmente estão trancadas na cabeça dos consumidores (KOTLER, ARMSTRONG, 2003, p. 118).
\end{abstract}

De acordo com a teoria criada por Maslow, as pessoas tentam primeiro satisfazer as necessidades básicas, como as fisiológicas - alimento e descanso - para após satisfazerem as necessidades de categorias superiores como segurança, estima e autorealização. A partir daí, pode ser visto que um conjunto muito mais complexo de questões está envolvido no processo de compra dos produtos do turismo, pois o processo envolve o consumidor num conjunto de decisões mais difíceis, num tempo de decisão mais lento e num nível de comprometimento mais elevado (SWARBROOKE; HORNER, 2002).

Para Swarbrooke e Horner (2002), é evidente que o comportamento do consumidor em turismo é, por si só, um tema que gera abundantes estudos acadêmicos. Contudo, ele também consiste numa questão de interesse crescente tanto para os praticantes do turismo quanto para as organizações que procuram estar à frente das mudanças nos gostos do consumidor, garantindo, com isso, a satisfação de suas necessidades. Sabe-se que, para ser bem-sucedido, o moderno marketing do turismo deve concentrar-se sempre no cliente.

As compras do consumidor são extremamente influenciadas pelas características culturais, sociais, pessoais, e psicológicas. A cultura é o principal determinante dos desejos e do comportamento de uma pessoa. O comportamento humano é em parte adquirido. Ao crescer em uma sociedade, uma criança adquire valores, percepções, desejos e comportamentos de sua família e de outras instituições importantes. Os fatores sociais são grupos como família, papéis sociais e status, em que o 
comportamento da pessoa é influenciado por diversos grupos, família e também status. Fatores pessoais influenciam também diretamente nas decisões do comprador, como idade e estágio no ciclo de vida, ocupação, situação financeira, estilo de vida, autoimagem e personalidade (KOTLER, ARMSTRONG, 2003).

\section{Elevado envolvimento na decisão de compra \\ Elevado comprometimento do consumidor}

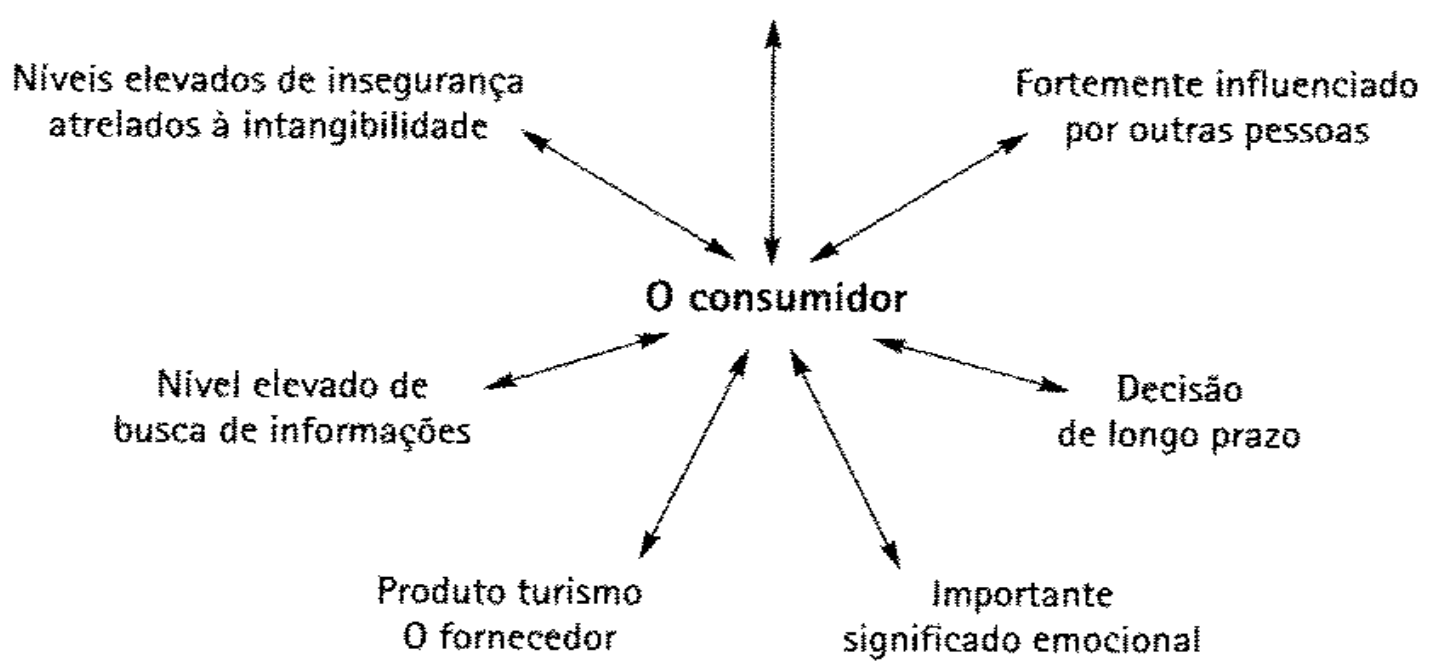

Figura 2: A complexidade do comportamento do consumidor em turismo - o lado da demanda. Fonte: Swarbrooke e Horner (2002, p. 110).

Swarbrooke e Horner (2002) definem o comportamento do consumidor de turismo como sendo "o estudo das razões de compra dos produtos pelas pessoas, e sobre o seu modo de tomar decisões". Para tal análise, faz-se necessário considerar um complexo grupo de variáveis que envolvem o consumidor de turismo na tomada de decisão, conforme o demonstrado na FIGURA 2.

Em termos muito gerais, uma decisão é a escolha de uma opção entre duas ou mais alternativas. Em outras palavras, para uma pessoa possa tomar uma decisão, é preciso que mais de uma alternativa esteja disponível (SHIFFMAN; KANUK, 2000).

Paralelamente ao emocional, há ainda a relação de outras pessoas que influenciam a decisão do comportamento que, segundo Swarbrooke e Horner (2002), podem ser os membros da família do comprador e/ou outros grupos de referência aos quais ele participa, tornando de difícil identificação as influências de terceiros no comportamento do comprador, mas que, como apontado por Kotler e Armstrong (2003), existem e servem para direcionar o consumidor.

O consumidor de produtos e serviços turísticos objetiva uma fuga do seu ambiente de trabalho e da rotina cotidiana que a vida urbana ocasiona, segundo Swarbrooke e Horner (2002), portanto, o comportamento do consumidor é carregado de significado consideravelmente emocional.

Há também diversos outros fatores que pesam na decisão de compra do consumidor. O preço quase sempre parece ser uma constante, não importando o setor do turismo em questão. O local é outro fator importante, seja da área de uma cidade em que um hotel se encontra, o aeroporto de partida oferecido por uma agência de viagens, ou a 
distância entre uma atração e a casa do visitante. Também se pode pressupor que a experiência anterior do turista com os serviços de uma empresa também será relevante para as decisões de compra em todos os setores do turismo (SWARBROOKE; HORNER. 2002).

Kotler e Armstrong (2003) dizem que existem cinco estágios que mostram o modo como os consumidores tomam suas decisões de compra:

1. Reconhecimento da necessidade, que é quando o comprador reconhece um problema ou uma necessidade, percebe a diferença entre seu estado atual e seu estado desejado.

2. Busca por informações, quando um consumidor interessado pode ou não buscar informações adicionais, ou seja, quando ele armazena sua necessidade na memória ou empreende uma busca por informações relacionadas à determinada necessidade.

3. Avaliação das alternativas de forma com que estabeleça atitudes em relação a diferentes marcas por meio de alguns procedimentos de avaliação, o modo como cada consumidor avalia alternativas de compra é totalmente característico de sua pessoalidade.

4. Decisão, o consumidor decide o que comprar, geralmente escolhendo em item relacionado à sua marca favorita.

5. Comportamento pós-compra, que mostra a satisfação ou insatisfação do consumidor com a compra de determinado produto ou serviço.

A tentativa de entender o comportamento de compra recebe vários nomes: mapeamento do sistema de consumo, do ciclo de atividade do cliente ou do cenário do cliente. Entender o comportamento do comprador em cada etapa, assim como as influências que ele recebe é a obrigação do profissional de marketing. Ver as atitudes dos outros, os fatores situacionais imprevistos e o risco percebido podem afetar a decisão de compra, bem como os níveis de satisfação pós-compra e as ações póscompra por parte da empresa (PORTELA, 2010).

O comportamento dos turistas apresenta variações entre grupos em função do fato de que os fatores determinantes pessoais ou externos variam de acordo com a personalidade e o estilo de vida (OLIVEIRA, 2007).

Pode-se considerar que os indivíduos mais extrovertidos estão mais propensos a avaliar positivamente as opiniões de amigos e parentes, segundo Swarbrooke e Horner (2002). E que os indivíduos introvertidos confiam mais em experiências próprias a fim de decidir a compra de uma destinação turística.

Já os consumidores de nível cultural mais elevado, que tenham contato com programas novos de televisão com regularidade e se interessam por questões sociais ou de âmbito mundial, segundo apontamento de Swarbrooke e Horner (2002), sofrem as influências externas e decidem a viagem em decorrência de um conjunto de informações coletadas nos diversos meios de comunicação.

\subsection{Processo de decisão de compra}

O processo de tomada de decisão do turista é complexo e envolve fatores externo e interno ao mesmo tempo. Em uma viagem, o turista deve tomar decisões antes e mesmo durante toda a viagem, tendo que decidir o destino, os meios de hospedagem, 
o transporte, a duração, o período, a empresa da qual comprar, além dos passeios diários do local (TRIGUEIRO, 2009).

Um fator importante é o relacionamento da organização com o consumidor. Em meio à crescente competitividade e mudanças, o marketing de relacionamento em uma organização poderá oferecer condições à empresa de conhecer as necessidades e as preferências de seus clientes, assim como verificar quais são os pontos fortes, neutros e, principalmente, deficientes em sua organização ou, até mesmo, dos seus concorrentes. Portanto, cabe ressaltar a importância e a necessidade do Marketing de Relacionamento com o cliente em uma organização. Em face dessa contingência do mercado, as organizações precisam ir além do marketing com enfoque voltado aos clientes. É preciso também que as organizações procurem aliados, junto aos fornecedores e aos distribuidores para desenvolver um sistema de rede cooperativo para atender melhor às necessidades dos clientes (KOTLER, 2000). Ainda segundo Kotler (2000), o marketing de relacionamentos possibilita que as relações entre as organizações e os clientes passem a ter um caráter mais duradouro do que simples transações eventuais. As organizações procuram também conhecer mais o consumidor, ouvindo-o, dedicando-se a ele; agradando-o e antecipando em atender os seus desejos, enfim, cativando-os. Essa nova forma de relacionamentos foi denominada de marketing um-a-um e customização maciça.

Num mercado de escolhas ilimitadas, as empresas concorrem ferozmente pela fidelização do cliente, o que requer criação e manutenção de relacionamento duradouro entre eles. A credibilidade se apresenta como a chave do processo de fidelização do cliente e do posicionamento da empresa (KOTLER E KELLER, 2006).

$\mathrm{O}$ desenvolvimento de relacionamento depende das interações entre as pessoas. Com o tempo, ambas as partes aprendem sobre habilidades e incertezas da outra. Em um relacionamento de longo prazo, a confiança mutua é importante. A distância pode também ter uma influência nos relacionamentos (KOTLER E KELLER, 2006). Os relacionamentos são valiosos porque criam eficiência e inovação para a empresa, criando assim um vínculo com o consumidor.

Abdalla et. al. (2013), baseados em sua pesquisa, afirmam que a lealdade dos turistas de Angra dos Reis (RJ) está ligada às questões estruturais, de atendimento e de comprometimento. Os turistas também consideram a comunicação "boca a boca" fundamental para escolha do local a serem hospedados.

\section{Método de Pesquisa}

A unidade de análise foi a Pousada Vale do Caparaó, localizada na cidade de Alto Caparaó (MG), área muito conhecida pelo turismo oferecido na região, totalmente ligada ao Pico da Bandeira, sua principal atração. A pousada está localizada no ponto turístico de Alto Caparaó, tendo ótima vista para as montanhas e sendo muito próxima das famosas cachoeiras da região, tendo acesso a elas a cerca de 15 metros; essa pousada é muito frequentada por pessoas que buscam tranqüilidade, maior contato com a natureza e também lazer, sendo assim visitada por todo tipo de turistas, desde universitários até aposentados.

Para obtenção dos resultados almejados, foi realizada uma pesquisa do tipo descritiva que faz o estudo, a análise, o registro e a interpretação do diferencial da pousada sem interferência do pesquisador. "As pesquisas deste tipo têm como objetivo primordial a descrição das características de determinada população ou fenômeno ou 
estabelecimento de relações entre variáveis" (GIL, 1999, p.44). Embora transmitam, inicialmente, uma ideia de que apenas relatam ou descrevem determinada situação, elas têm como objetivo principal estabelecer relações entre as variáveis analisadas e levantar hipóteses ou possibilidades para explicar essas relações (BERTUCCI, 2009, p.50).

A técnica implantada na pesquisa foi a de levantamento, também conhecida como surveys, essas pesquisas são realizadas tanto para descrever, quanto para explicar ou explorar dado fenômeno (BERTUCCI, 2009).

\begin{abstract}
As pesquisas deste tipo se caracterizam pela interrogação direta das pessoas cujo comportamento se deseja conhecer. Basicamente, procede-se à solicitação de informações a um grupo significativo de pessoas acerca do problema estudado para em seguida, mediante análise quantitativa, obter as conclusões correspondentes dos dados coletados (GIL, 1999, p.70).
\end{abstract}

A pesquisa foi quantitativa, em que os clientes preencheram questionários compostos por questões fechadas que foram respondidas na pousada Vale do Caparaó. As informações foram colhidas por meio de um questionário estruturado com 21 perguntas claras e objetivas. Isso garante uniformidade de entendimento dos entrevistados. A coleta de dados compreendeu o período de 01 de outubro a 30 de novembro de 2014.

Para Cervo e Bervian (1996), o questionário é a forma mais usada para coletar dados, pois possibilita medir com melhor exatidão o que se deseja, sendo um meio de obter respostas às questões por uma fórmula que o próprio informante preenche. Todo questionário tem que ter natureza impessoal para assegurar uniformidade na avaliação de uma situação para outra.

A pesquisa foi feita de forma quantitativa, teve como objetivo identificar a presença e medir a frequência e a intensidade de comportamentos, atitudes e motivações de um determinado público-alvo. Gerando medidas precisas e confiáveis, pois se baseia em amostras estatisticamente confiáveis. Com base em questionários estruturados em que o entrevistador segue um roteiro previamente estabelecido. Não é permitido adaptar as perguntas a determinada situação, inverter a ordem ou elaborar outras perguntas (CERVO e BERVIAN, 1996).

Utilizou-se a metodologia proposta por Levine (2000) para calcular o número mínimo de amostras com finalidade de obter intervalo de confiança de $95 \%$, em que o erro máximo de estimativa seja de 0,10 , adotando o valor crítico $(Z \alpha / 2)$ como 1,96 . Com isso, verificou-se que o número mínimo de amostras é de aproximadamente 97 unidades amostrais. Proposta essa que só é utilizada quando não se conhece o universo a ser pesquisado.

$$
n=\frac{Z_{\alpha / 2}^{2} * 0,25}{E^{2}} \quad n=\frac{1,96^{2} * 0,25}{0,10^{2}} \cong 97
$$

Foram aplicados questionários para 97 turistas/clientes de forma aleatória, já que não se tem conhecimento do universo por se tratar dos clientes em uma forma geral e não de grupos específicos. 
Os critérios utilizados acerca da análise de dados foram a verificação de gráficos para expressar os resultados obtidos com pesquisa feita, obtendo assim todas as informações necessárias acerca do problema de pesquisa.

\section{Análise dos Resultados}

Os resultados da pesquisa realizada procuraram relacionar o referencial teórico através dos dados a seguir, dando valor científico a toda análise, uma vez que se interligaria com o referencial e com os autores ali apresentados de forma que os resultados obtidos pudessem ser apresentados, resolvendo assim o problema de pesquisa.

$\mathrm{Na}$ parcela de amostra dos turistas analisados, percebeu-se que as diferenças entre o gênero feminino e o masculino foram de $10 \%$, sendo, em sua maioria, masculinos (55\%). Os clientes com faixa etária preponderante entre 15 e 35 anos, representaram $65 \%$ dos clientes da pousada. $\mathrm{Na}$ amostra, foram coletados dados extraídos da opinião de 97 turistas que frequentaram a Pousada Vale do Caparaó entre o período de Outubro/Novembro de 2014, dentre os quais, a maior parte é solteira, perfazendo-se $53 \%$ da análise, além disso, a maioria dos informantes não possui filhos, cerca de $56 \%$ dos entrevistados. Esses resultados mostram um alto índice de turistas jovens e solteiros representando a maioria dos clientes, o que demonstra que o público de adolescentes e adultos são os que têm maior hábito de optar por esse tipo de serviço e hospedagem.

Uma questão fundamental aplicada aos turistas visava saber por que o turista escolheu se hospedar na pousada Vale do Caparaó, com opções que variam de acesso, localidade, estrutura, clima e outros. Conforme expresso no gráfico 1, destacou-se a escolha pela estrutura com cerca de $55 \%$ dos resultados obtidos e também a sua localidade com $25 \%$, esta, por sua vez, destaca-se dentre as outras de acordo com os clientes.

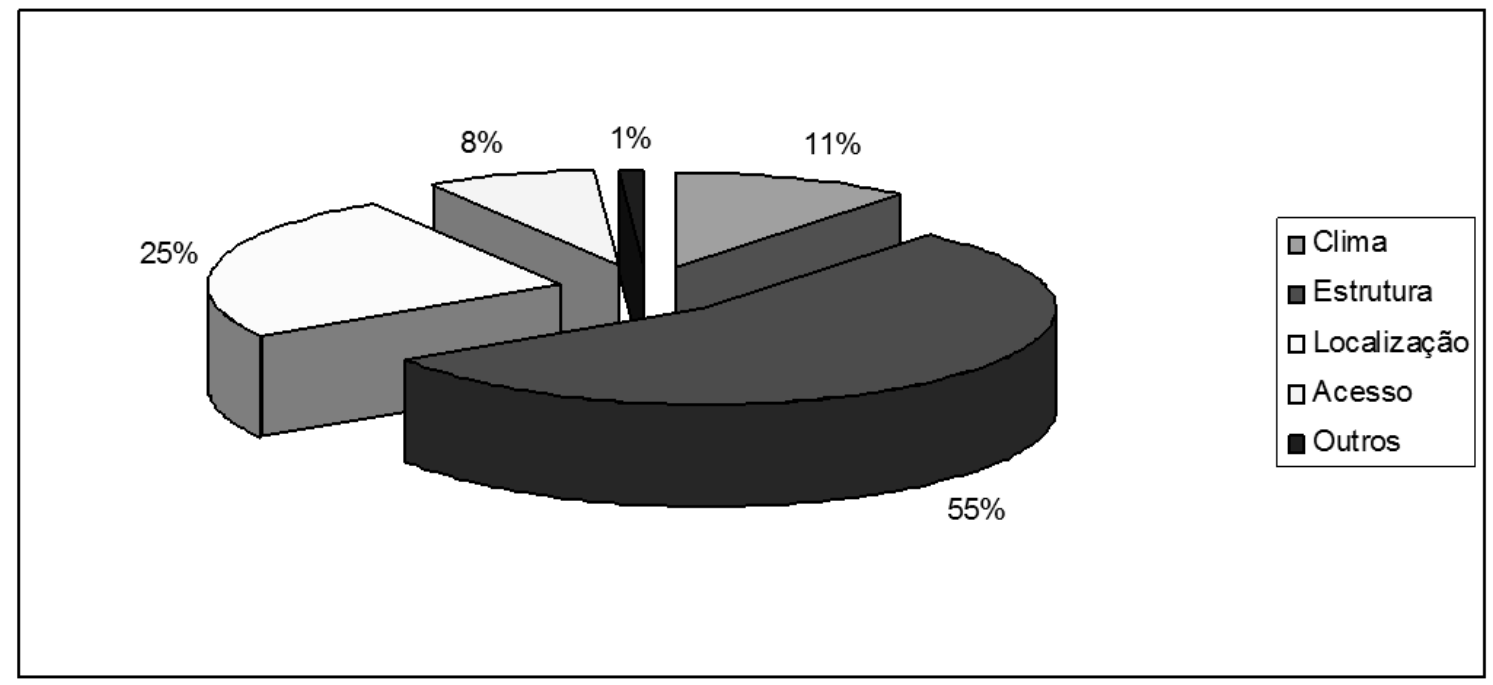

Gráfico 1: Motivos que levaram a se hospedarem na pousada Vale do Caparaó Fonte: Dados de pesquisa.

Seguindo o roteiro do questionário, abordou-se também como o cliente ficou sabendo da pousada Vale do Caparaó. Sobressaindo-se, assim, a opção que assinalava 
que o motivo seriam as recomendações de amigos, com cerca de $56 \%$ dos resultados (GRÁFICO 2). Foi apontado ainda que uma forte taxa dos clientes (36\%) tomou conhecimento da pousada através da internet, o que é explicado pela de idade dos clientes (maioria entre 14 e 35 anos), uma vez que estes são mais ligados a computação e aos meios de pesquisas através da internet.

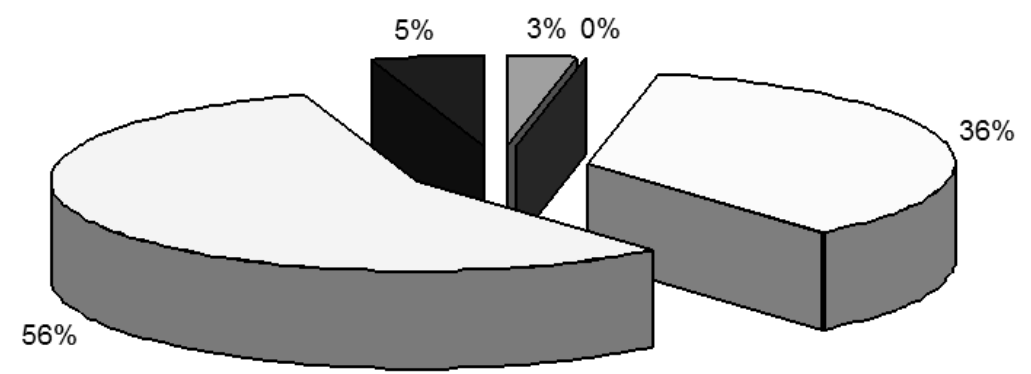

Gráfico 2: Como tomaram conhecimento da pousada Vale do Caparaó Fonte: Dados de Pesquisa.

A pesquisa revelou também a avaliação sobre a pousada, em que os clientes realizaram uma observação geral, avaliando também sua experiência lá, suas análises a respeito do preço desta, com opções que variaram de péssimo a excelente. Segundo o gráfico 3, a avaliação geral teve um padrão de ótimo, cerca de 59\% dos resultados, tendo também uma boa representação de excelência com $30 \%$.

Quando questionados sobre a experiência passada na pousada, os turistas afirmaram ter sido ótima por $52 \%$ dos clientes e outros $37 \%$ avaliaram-na como excelente (GRÁFICO 3). Esses números, se somados, chegam a $89 \%$ dos turistas, podendo apresentar alto índice de satisfação com a Pousada Vale do Caparaó, fator este fundamental para um possível retorno e, até mesmo, indicações para turistas em potencial que ainda não conhecem a pousada. Clientes de serviços tendem a indicar aos amigos suas experiências positivas, tornando-se assim poderosas ferramentas de marketing boca-a-boca.

Ainda conforme o gráfico 3, quando questionados quanto ao preço, houve um empate na pesquisa com $45 \%$ afirmando que o preço era normal e $45 \%$ que o preço ótimo. Esses resultados obtidos através dos clientes mostram-se satisfatórios, evidenciando que o turista reconhece o valor da prestação de serviço contratada e julga justo o valor por ele pago. 


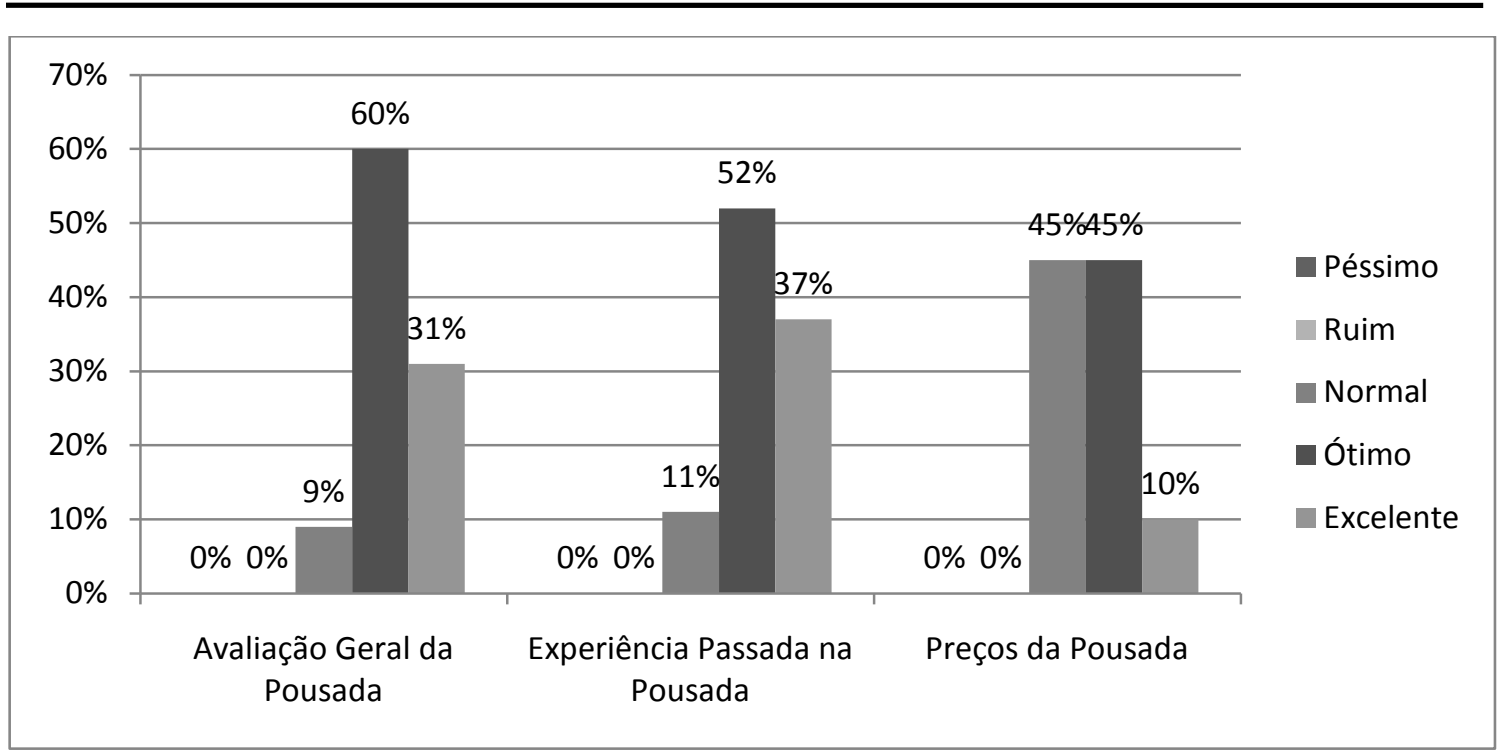

Gráfico 3: Avaliação geral sobre a Pousada Vale do Caparaó

Fonte: Dados de pesquisa.

Dando sequência à análise dos dados do questionário, foram realizadas perguntas sobre experiências anteriores em outras pousadas ou hotéis localizados na cidade de Alto Caparaó. Questionando se os informantes já haviam se hospedado em alguma pousada da cidade antes, cerca de $68 \%$ dos clientes afirmaram não terem feito visitas em outras pousadas na cidade, tornando-se assim uma limitação de pesquisa, pois a maioria não pode expressar opiniões sobre as pousadas concorrentes localizadas na região, para uma maior apuração de amostras.

Os clientes que já haviam se hospedado em outras opções pousadas do município anteriormente, foram questionados em qual(is) pousada(s) eles ficaram hospedados, a resposta mais apontada foi a Concorrente A, com 22\%, de acordo com gráfico 4. Esse fato aponta para o principal concorrente, conforme o perfil dos consumidores da Pousada Vale do Caparaó, devendo a gestão da pousada estar atenta não somente a ela, mas também às concorrentes em potencial, bem como às novas entrantes no mercado.

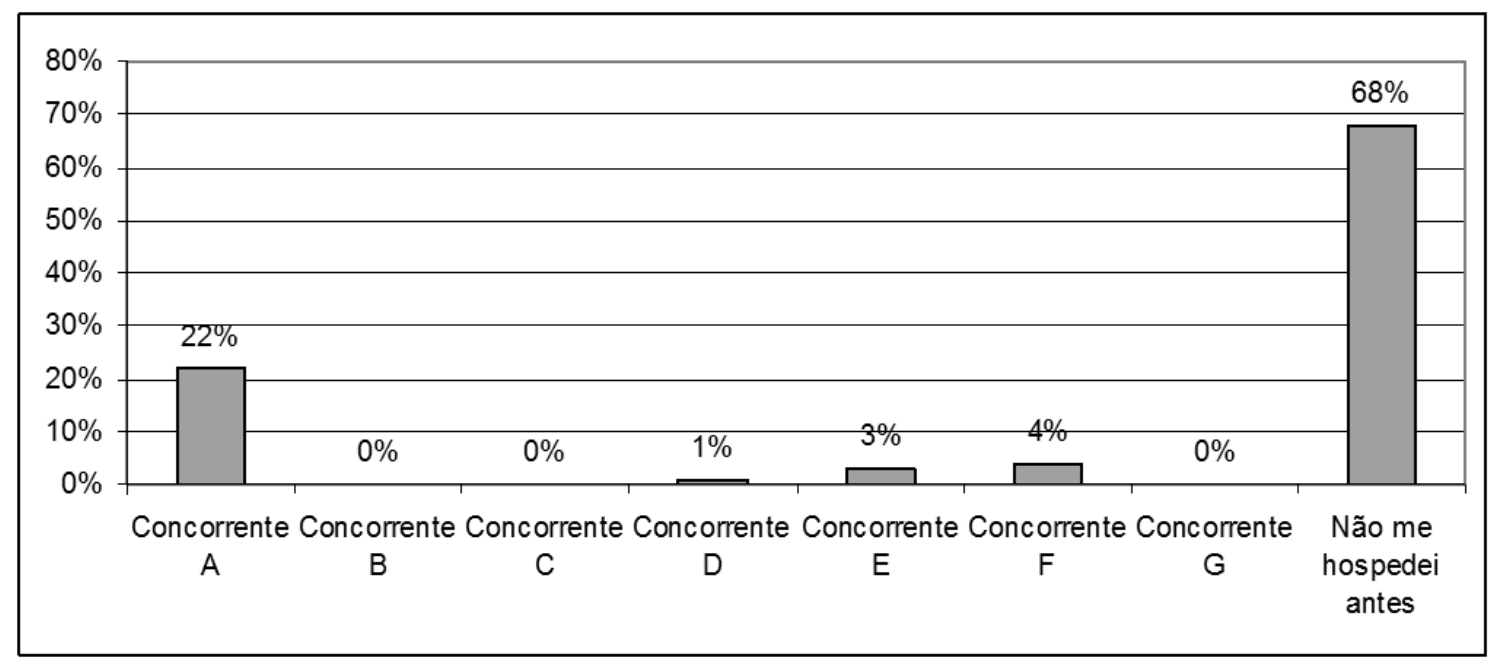

Gráfico 4: Hospedagem em outras pousadas ou hotéis da cidade.

Fonte: Dados de pesquisa. 
Ainda para os clientes que já frequentaram outras pousadas, foram feitas perguntas em relação ao desempenho das outras Pousadas perante a pousada Vale do Caparaó. Em relação à infraestrutura, 90\% dos clientes afirmaram que as outras pousadas possuem infraestrutura inferior. Esse fator é fundamental na prestação de serviços pela sua intangibilidade, uma vez que o turista procura evidências físicas para tangibilizar a qualidade do serviço prestado.

Em relação ao atendimento, $76 \%$ dos clientes dizeram que o atendimento da Pousada Vale do Caparaó é melhor do que os concorrentes. Se por um lado, as opções de lazer em torno do Pico da Bandeira são praticamente iguais para os turistas de todas as pousadas, por outro, $\mathrm{o}$ atendimento poderá ser um diferencial entre as organizações.

Em relação ao preço, $48 \%$ dos clientes apontaram que o preço das concorrentes é superior em relação à Pousada Vale do Caparaó. Isso pode sinalizar que os consumidores enxergam valor nos serviços prestados pela pousada e acham justo o valor pago.

Em relação à localização, 93\% dos turistas disseram que a pousada Vale do Caparaó apresenta localização melhor do que as demais. O fato de os turistas conseguirem visualizar o ponto da Pousada Vale do Caparaó como superior às concorrentes é importante para a empresa e deve ser considerado em suas estratégias para crescimento no mercado em suas futuras ações estratégicas.

Sobre os serviços prestados, cerca de $79 \%$ dos clientes afirmaram que os serviços prestados da pousada Vale do Caparaó são melhores que das suas concorrentes. Assim como no atendimento, os demais serviços da pousada são valorizados e, conforme o resultado, entende-se haver uma satisfação dos consumidores quanto à prestação de serviços.

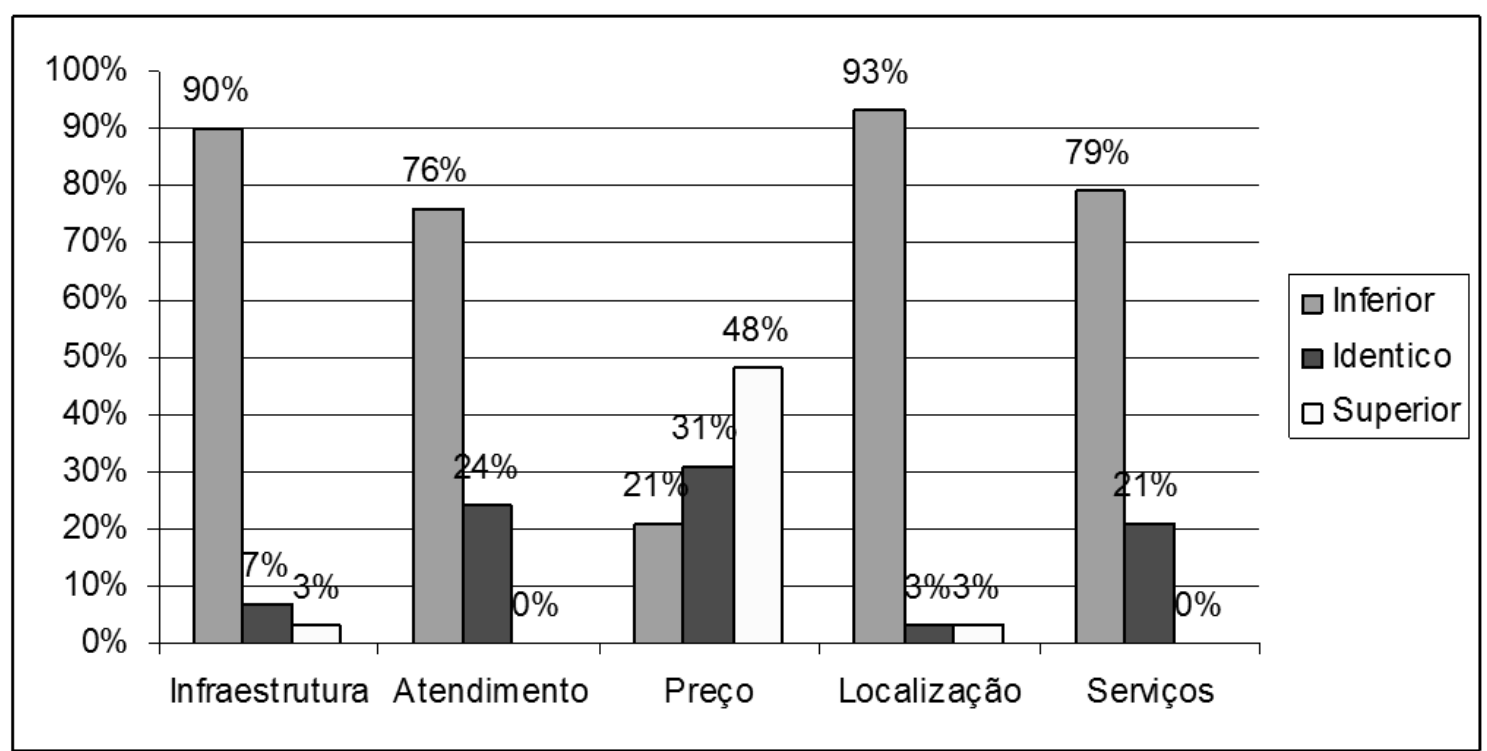

Gráfico 5: Aspectos comparativos das concorrentes em relação à Pousada Vale do Caparaó. Fonte: Dados de pesquisa.

Quando questionados se recomendariam a pousada Vale do Caparaó para outras pessoas, os resultados atingiram a totalidade dos consumidores afirmando que sim, evidenciando, portanto, a satisfação dos entrevistados em relação à instituição objeto de 
pesquisa. Esse índice de satisfação pode estar diretamente ligado aos dados apresentados no gráfico 5, em que os consumidores reconheceram a superioridade da pousada nos quesitos: infraestrutura, atendimento, localização e serviços. Lembrando ainda que os clientes reconhecem os preços da pousadas mais acessíveis quando afirmam que o preço é inferior ao dos concorrentes.

Finalizando os questionamentos, foram realizadas perguntas sobre o principal motivo que os atraiu para se hospedarem na pousada Vale do Caparaó. Em conformidade com o gráfico 6, a estadia em si foi o fator mais apontado com a aprovação de $39 \%$ dos clientes, sendo a localização o segundo fator mais citado, com $32 \%$.

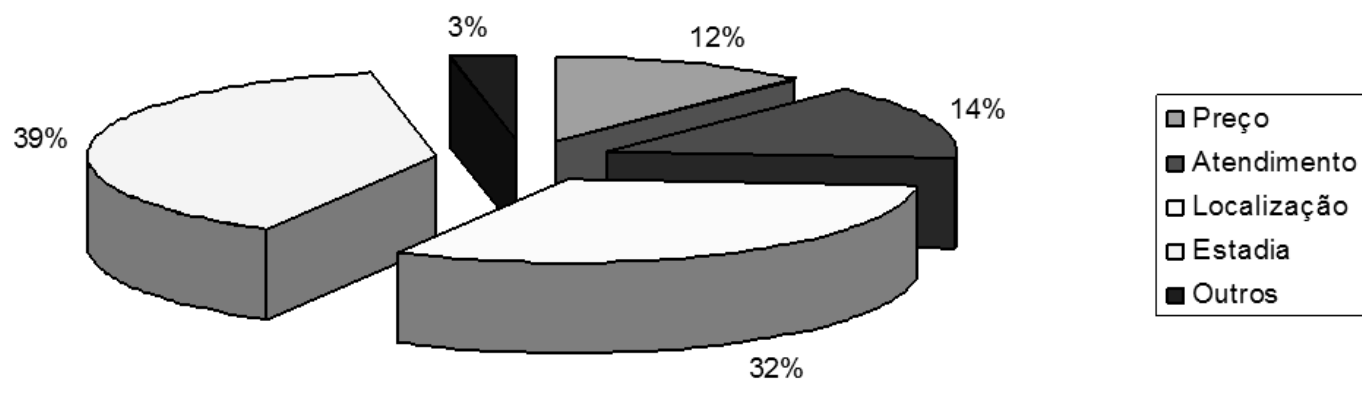

Gráfico 6: Atração para hospedagem.

Fonte: Dados de pesquisa.

Quando interrogados sobre os pontos fortes da Pousada Vale do Caparaó, 49\% dos clientes citaram a infraestrutura como seu principal ponto forte, seguido pela estadia com 25\% (GRÁFICO 7). Esses dados fortalecem as repostas anteriores apontadas nos gráficos 5 e 6 .

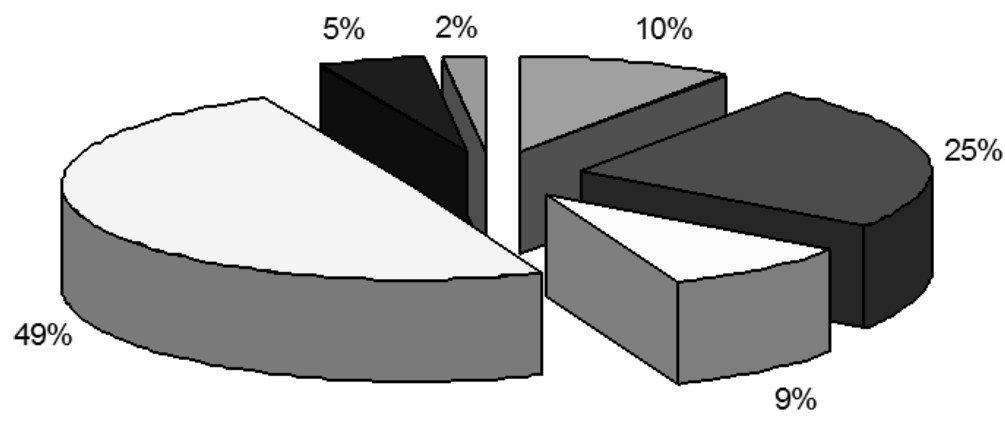

$\square$ Atendimento

$\square$ Estadia

$\square$ Localização

$\square$ Infraestrutura

- Serviços

口Outros

Gráfico 7: Pontos fortes da Pousada Vale do Caparaó

Fonte: Dados de pesquisa. 


\section{Conclusões}

Buscou-se proporcionar uma maior percepção sobre a visão do cliente perante toda estrutura da Pousada Vale do Caparaó, desde seu acesso até seu atendimento. A pesquisa realizada levou também a um maior entendimento sobre a visão do cliente acerca da Pousada.

A pesquisa foi importante para a Pousada Vale do Caparaó, pois se pôde tomar conhecimento da opinião dos clientes, identificando um vasto leque de fatores em que a pousada sobressai dentre as outras e também fatores em que ela deixa a desejar. Assim como defendido por Kotler e Armstrong (2003), a satisfação dos consumidores depende da percepção que eles têm da qualidade dos serviços prestados bem como da estrutura.

A pesquisa feita abordou opiniões dos turistas sobre pousada Vale do Caparaó e a comparação com suas concorrentes, avaliando atendimento, clima, estadia, infraestrutura, preço, localidade, acesso, serviços prestados. Os usuários consideraram que a pousada se encontra em situação privilegiada nos seguintes pontos: infraestrutura; atendimento e localização. $\mathrm{O}$ atendimento está ligado à forma como a organização se relaciona com o consumidor, fato este relatado como positivo e que reforça os conceitos de Kotler (2000) a respeito da relação com cliente, considerando que esta deve ser duradoura e de Kotler e Keller (2006), segundo esses autores, a credibilidade se apresenta como a chave do processo de fidelização do cliente e do posicionamento da empresa.

Os dados apontaram também para a maneira como os consumidores tomaram conhecimento da existência da Pousada e foi relatada a indicação de amigos e parentes como principal motivo, isso reforça a satisfação com a organização, uma vez que, segundo Kotler (2000), clientes satisfeitos tendem a se tornarem agentes de propagação das organizações. Essas respostas são condizentes com a pesquisa de Abdalla et. al. (2013, p. 101) que assevera "que tanto o comprometimento do cliente para com o estabelecimento quanto sua predisposição em recomendar a pousada apresentaram relação direta com a predição das intenções de lealdade." Dessa forma, fica clara a necessidade de repensar o relacionamento com os turistas e pautar as ações estratégicas com o foco nesse prisma, para que, assim, possam vir a obter melhores resultados operacionais.

Com a pesquisa feita, foi possível perceber também um grande destaque da Pousada Vale do Caparaó perante as outras empresas. Enfim, neste artigo, foram adquiridas várias informações importantes sobre fatores que levam os clientes a frequentarem a Pousada Vale do Caparaó e a não frequentarem as diversas outras Pousadas localizadas na região. Com a apuração dos dados, percebeu-se que a pousada analisada se destaca pela sua infraestrutura superior, por sua estadia e também pela facilidade de acesso, de acordo com a visão do cliente. Os clientes julgam justo o valor pago pelos serviços, esses pontos vão ao encontro dos relatados pelos autores Swarbrooke e Horner (2002) que afirmam que os clientes do turismo valorizam o local e dão importância ao fator preço nessa relação.

Um dos pontos mais importantes que a pesquisa revelou é que cerca de apenas 1/3 dos clientes visitou outras Pousadas e Hotéis dentro da cidade de Alto Caparaó. Este fator pode ser positivo para a pousada estudada, pois mostra que ela foi a primeira opção para $68 \%$ dos clientes. No entanto, no momento da pesquisa, esse fator foi limitante, uma vez que não foi possível uma maior comparação entre a Pousada Vale do Caparaó e seus concorrentes. 
Como relatado por Trigueiro (2009), a tomada de decisão por parte dos consumidores é complexa, sendo assim, a pousada deve estar atenta aos fatores que interferem nesse momento. Os administradores devem ainda, sempre que possível, ouvir os clientes e verificar se seus pontos fortes estão se mantendo, procurando fortalecê-los. Além disso, deve ainda estar atento a todos os concorrentes, tanto atuais quanto potenciais, para que não seja surpreendida com relação a isso.

Enfim, recomenda-se que novas pesquisas sejam realizadas na cidade e nas demais pousadas para que novos dados sejam levantados e utilizados na tomada de decisão das empresas ligadas ao turismo local. Turismo não se faz de maneira isolada e tem-se a necessidade de ter uma visão holística do município, conhecendo suas potencialidades e fragilidade e, assim, em conjunto com comunidade e empresas privadas, conseguirem satisfazer a necessidades dos turistas.

\section{Referências}

ABDALLA, M. M. et al. Lealdade aos meios de hospedagem: um estudo com turistas de pousadas de Angra dos Reis. Revista Turismo e sociedade, abr/jun, 2009. Disponível em: <http://ojs.c3sl.ufpr.br/ojs/index.php/turismo/article/view/27767/19856> Acesso em: 13 set. 2014.

BERTUCCI, J. L. O. Metodologia básica para elaboração de trabalhos de conclusão de curso (TCC): Ênfase na elaboração de TCC de pós-graduação Lato Sensu. 2. ed. , São Paulo: Atlas, 2009.

CHAGAS, M. M.; MARQUES, S.; BRANDÃO, P.M. "Fatores influenciadores da satisfação e fidelidade ao destino turístico pipa/rn: Uma análise a partir do instrumento servqual adaptado". Revista Turismo, v.3, ano 4, Nov/Dez. 2010-2011. Disponível em: 〈www6.univali.br/seer/index.php/rtva/article/view/2502> Acesso em: 13 set. 2014.

CERVO, A. L.; BERVIAN, P. A. Metodologia Científica. 4. ed. São Paulo: MAKRON, 1996.

GIL, A. C. Métodos e técnicas de pesquisa social. 5. ed. São Paulo: Atlas, 1999.

GRÖNROOS, C. Marketing: gerenciamento e serviços. Rio de Janeiro: Elsevier, 2004.

KOTLER, P. Administração de Marketing. 10. ed. São Paulo: Prentice Hall, 2000.

KOTler, P.; ARMStRONG, G. Princípios de marketing. 9. ed. São Paulo: Atlas, 2003.

Princípios de marketing. 9. ed. São Paulo: Prentice Hall, 2005.

KOTLER, Phillip; KELLER, Kevin L. Administração de Marketing. 12. ed. São Paulo: Pearson, 2006. 
LEVINE, D.M.; BERENSON, M.L.; STEPHAN, D. Estatística: Teoria e Aplicações. Rio de Janeiro: LTC, 2000

OLIVEIRA, F. F. Comportamento do consumidor: um estudo das teorias de marketing aplicadas ao turismo. 2007. Disponível em: s http://www.iptan.edu.br/publicacoes/saberes_interdisciplinares/pdf/revista02/Comporta mento\%20do\%20consumidor\%20um\%20estudo\%20das\%20teorias\%20de\%20marketin g\%20aplicadas\%20ao\%20turismo.pdf > Acesso em : 14 set. 2014.

PORTELA, C. B. Marketing e o comportamento do Consumidor. São Paulo, abr/ jun. 2010. Disponível em: <convibra.com.br/upload/paper/adm/adm_3488.pdf > Acesso em: 13 set. 2014.

SEBRAE. Serviço de apoio às Micro e pequenas empresas. 10 anos de monitoramento da sobrevivência e mortalidade de empresas. SEBRAE - SP. 2008. Disponível em: < http://www.sebraesp.com.br/arquivos_site/biblioteca/EstudosPesquisas/mortalidade/10_ anos_mortalidade_relatorio_completo.pdf >. Acesso em 20 mai. 2016.

SHIFFMAN, L.; KANUK, L.L. Comportamento do consumidor. 6. ed. Rio de Janeiro: LTC. 2000.

SWARBROOKE, J.; HORNER, S. Comportamento do consumidor no turismo. São Paulo: Atlas, 2002.

TRIGUEIRO, K. Novas tendências do consumidor de turismo na nova economia. Departamento de turismo - UFOP. Abr/Jun. 2009. Disponível em: $<$ http://www.google.com.br/url? sa=t\&rct=j\&q=\&esrc=s\&source=web\&cd=1\&cad= rja\&uact $=8 \& v e d=0 \mathrm{CB} 0 \mathrm{QFjAA} \& u r l=\mathrm{http} \% 3 \mathrm{~A} \% 2 \mathrm{~F} \% 2 \mathrm{Fwww} \cdot$ setur.ufop.br\%2Fartigo01 .pdf\&ei=9fVtVMDLEMehgwTj94OABw\&usg=AFQjCNGYgI2PvTvKsyKanPjrg-ZEo3fNA\&bvm=bv.80120444,d.eXY> Acesso em: 14 set. 2014.

VAZ, G. N.; PERIM, J.Y. Marketing turístico: receptivo e emissivo: um roteiro estratégico para objetos mercadológicos públicos e privados. São Paulo, 2001.

WHITELEY, R.; HESSAN, D. Crescimento orientado para o cliente: cinco estratégias comprovadas para criar vantagem competitiva. Rio De Janeiro, Campus, 1996. 